\title{
Can drying and re-wetting of magnesium sulfate salts lead to damage of stone?
}

\author{
Enrica Balboni · Rosa M. Espinosa-Marzal • \\ Eric Doehne · George W. Scherer
}

Received: 19 May 2010/Accepted: 27 September 2010/Published online: 21 October 2010

(C) Springer-Verlag 2010

\begin{abstract}
Magnesium sulfate salts have been linked to the decay of stone in the field and in laboratory experiments, but the mechanism of damage is still poorly understood. Thermomechanical analysis shows that expansion of stone contaminated with magnesium sulfate salts occurs during drying, followed by relaxation of the stress during dehydration of the precipitated salts. We applied thermogravimetric analysis and X-ray diffractometry to identify the salt phases that precipitate during drying of bulk solutions. The results show the formation of 11 different crystal phases. A novel experiment in which a plate of salt-laden stone is bonded to a glass plate is used to demonstrate the existence of crystallization pressure: warping of the composite reveals significant deformation of the stone during rewetting of lower hydrates of magnesium sulfate. Environmental scanning electronic microscope (ESEM)/STEM experiments show that hydration of single crystals of the lower hydrates of magnesium sulfate is a through-solution crystallization process that is only visible at a small scale $(\sim \mu \mathrm{m})$. It is followed by growth of the crystal prior to
\end{abstract}

E. Balboni · E. Doehne

Getty Conservation Institute, Los Angeles, USA

R. M. Espinosa-Marzal · G. W. Scherer

Civil and Environmental Engineering, Princeton University,

Princeton, USA

R. M. Espinosa-Marzal

Empa, Swiss Federal Laboratories for Material Science

and Technology, Dübendorf, Switzerland

Present Address:

R. M. Espinosa-Marzal ( $₫)$

Surface Science and Technology, ETH Zurich, Zürich, Switzerland

e-mail: rosa.espinosa@mat.ethz.ch deliquescence. This demonstrates that crystallization pressure is the main cause of the stress induced by salt hydration. In addition, we found that drying-induced crystallization is kinetically hindered at high concentration, which we attribute to the low nucleation rate in a highly viscous magnesium sulfate solution.

Keywords Salt damage - Salt crystallization · Magnesium sulfate

\section{Introduction}

Salt crystallization is responsible for severe damage of stone and masonry in historic structures (Goudie and Viles 1997). Recently, research on the intense damage of dolomitic limestone was found to be related to phase changes of magnesium sulfates salts in the pores of the stone (LopezArce et al. 2008; Doehne and Pinchin 2008). Magnesium sulfate is also commonly related to weathering processes on Earth (Evans 1969) and on Mars (Gooding 1992; Clark and Van Hart 1981). Laboratory experiments confirm that magnesium sulfate is capable of causing the stone to fracture (Ruiz-Agudo et al. 2007a). However, it is still not well-understood by which phase and under which conditions damage is generated.

The goal of this work is to study the mechanisms by which stone is damaged during in-pore crystallization of magnesium sulfate salts. Thermomechanical analysis (TMA) (Espinosa-Marzal and Scherer 2009) and warping experiments (Espinosa-Marzal et al. 2010) are used to measure the deformations under drying and re-wetting conditions, respectively. We show that the in-pore crystallization of magnesium sulfate salts is capable of generating significant deformations of the stone at low salt 
contents. We identify the crystalline phases that form during drying of bulk solution by using a combination of $\mathrm{X}$-ray diffractometry (XRD), and thermogravimetric analysis (TGA) techniques. That the crystallization pressure is the main cause of damage during hydration is confirmed by studying the hydration of single crystals of micrometer size with environmental scanning electronic microscope (ESEM)/STEM.

\section{Background}

The system $\mathrm{MgSO}_{4}+\mathrm{H}_{2} \mathrm{O}$ has three stable crystalline phases in the terrestrial atmosphere: epsomite $\left(\mathrm{MgSO}_{4} \cdot 7 \mathrm{H}_{2} \mathrm{O}\right)$, hexahydrite $\left(\mathrm{MgSO}_{4} \cdot 6 \mathrm{H}_{2} \mathrm{O}\right)$ and kieserite $\left(\mathrm{MgSO}_{4} \cdot 1 \mathrm{H}_{2} \mathrm{O}\right)$ (e.g. Steiger and Linnow 2008). At least 8 identified metastable crystalline phases with $1,1.25,2,3,4,5,11$ and 12 water molecules can form by hydration or dehydration of the stables salts (e.g. see Chipera and Vaniman 2007; Paulik et al. 1981) as well as one amorphous phase (Vaniman et al. 2004; Ruiz-Agudo et al. 2007b).

Hydration and dehydration of magnesium sulfate salts has been widely investigated, among others reasons owing to its presence in Mars, particularly because they might be a source of water in the martian atmosphere (Feldman et al. 2004; Vaniman et al. 2004; Chipera and Vaniman 2007).

Although kieserite is the stable phase at temperature above $71^{\circ} \mathrm{C}$, drying a solution at this or higher temperatures $\left(100^{\circ} \mathrm{C}\right)$ yields a mixture of hydrates in porous glass frits that gradually and slowly lose their water molecules. Freeze-drying of the pore solution and subsequent drying of the precipitated hydrated phases at $200^{\circ} \mathrm{C}$ over weeks, leads to pure kieserite (Steiger and Linnow 2008). Kieserite transforms to hexahydrite and epsomite as relative humidity increases, but discrepancies from equilibrium thermodynamics are found during the conversion. At room temperature, epsomite does not form at relative humidity (RH) larger than $51 \%$ in the pores of glass frits as predicted, but only hexahydrite forms at $80 \% \mathrm{RH}$ as measured by XRD (Steiger and Linnow 2008). Above $80 \%$ RH, epsomite forms through hydration of hexahydrite. This is in agreement also with the results of Wang et al. (2009) performed in bulk solution.

In contrast, epsomite and hexahydrite do not easily revert to kieserite on desiccation (Vaniman et al. 2004; Heide 1969). Epsomite transforms readily to hexahydrite at $50-55 \% \mathrm{RH}$ and $20^{\circ} \mathrm{C}$ and consequently hexahydrite is very likely to appear as efflorescence in the field (Foster and Hoover 1963). Further dehydration leads to lower hydrated phases depending on temperature and relative humidity.

Chipera and Vaniman (2007) conducted hydration/ dehydration experiments at temperatures from 3 to $75^{\circ} \mathrm{C}$ and $\mathrm{RH}$ from 6 to $74 \%$ and observed that starkeyite $\left(\mathrm{MgSO}_{4} \cdot 4 \mathrm{H}_{2} \mathrm{O}\right)$ forms during dehydration and it shows a pronounced stability field located between hexahydrite and kieserite. According to this, they extended the phase diagram of $\mathrm{MgSO}_{4} \cdot \mathrm{H}_{2} \mathrm{O}$ to starkeyite. Pentahydrite $\left(\mathrm{MgSO}_{4} \cdot 5 \mathrm{H}_{2} \mathrm{O}\right)$ was also observed often to form during dehydration.

Wang et al. (2009) performed hydration experiments of magnesium sulfate salts. According to them, starkeyite $\left(\mathrm{MgSO}_{4} \cdot 4 \mathrm{H}_{2} \mathrm{O}\right)$ remains stable below $54 \% \mathrm{RH}$. Above $54 \%$ $\mathrm{RH}$ starkeyite converts directly to $\mathrm{MgSO}_{4} \cdot 7 \mathrm{H}_{2} \mathrm{O}$ and goes through deliquescence above $94 \%$.

Discrepancies are found in the literature, e.g. about the duration of the transformations, but it must be taken into account that it strongly depends on the sample preparation and sample size which differs in the reported experiments.

Salts with large crystal-liquid interfacial energy and molecular volume require a higher supersaturation ratio, $\beta$, for nucleation (Espinosa-Marzal and Scherer 2008a) and therefore are more prone to cause damage. The liquidcrystal interfacial energy of epsomite was estimated through its enthalpy of dissolution to be $0.018 \mathrm{mN} / \mathrm{m}$, which leads to a small critical supersaturation for nucleation of epsomite, comparable to that of halite (EspinosaMarzal and Scherer 2010). Since the enthalpy of dissolution of hexahydrite must be smaller than that of epsomite, a similar trend is expected for hexahydrite. In (EspinosaMarzal and Scherer 2010), the nucleation rate is given as a function of solution properties (supersaturation and viscosity), crystal properties (crystal-liquid interfacial energy and molecular volume) and contact angle. Here it is shown that, for each salt, higher supersaturation initially enhances the nucleation rate according to the exponential dependence on $(\ln (\beta))^{2}$. However, if concentration increases further, the resulting increase of the viscosity leads to a decrease of the nucleation rate. This decrease is highly relevant for magnesium sulfate solution due to its high viscosity (CRC 2007), which acts as an obstacle for the nucleation of epsomite at high supersaturation. This suggests that crystallization of epsomite, and also of hexahydrite, might be kinetically hindered at high concentrations.

Many literature sources rank magnesium sulfate among the most damaging salts (Goudie et al. 1970; Goudie 1985, Cooke et al. 1993; Ruiz-Agudo et al. 2007a). Salt weathering has been related to the action of hydration pressure, owing to the increase of the volume occupied by the confined salts (Correns and Steinborn 1939; Steiger and Linnow 2008) and to the action of growth pressure exerted by confined salt crystals precipitating in the supersaturated pore solution (Correns and Steinborn 1939; Chatterji and Jensen 1989; Rodriguez-Navarro and Doehne 1999; Flatt 2002; Scherer 2004; Steiger 2005a, b; Coussy 2006).

The capillary uptake experiment of magnesium sulfate with simultaneous drying in calcarenite (Ruiz-Agudo et al. 
2007a) reveals differences between damage induced by sodium sulfate and magnesium sulfate salts. Magnesium sulfate tends to precipitate within a wider crystallization front and in pores of different size, while sodium sulfate is mainly concentrated close to the surface and in large pores. This different behavior is explained through differences in the solution properties, mainly the higher viscosity of the magnesium sulfate solution that retards the capillary flux causing evaporation to occur within the stone. The damage pattern appears as crack propagation in the bulk stone, the role of the precipitated crystals being to cement the stone and prevent collapse; hexahydrite and epsomite are identified on the basis of morphological and optical characteristics. As the authors report, it is unclear how damage is generated.

Steiger et al. (2008) measured the deformation suffered by glass frits during in-pore hydration of kieserite by Electronic Speckle Interferometry (ESPI). They report the occurrence of two different reaction pathways for the hydration of kieserite: at RHs below the deliquescence humidity of kieserite $\left(60 \%\right.$ at $\left.25^{\circ} \mathrm{C}\right)$ the reaction proceeds as a true solid-state reaction, while at RHs above the deliquescence humidity of kieserite a two step process, involving dissolution of kieserite followed by crystallization of hexahydrite, is suggested. The measured strain provides evidence that hydration of kieserite in confined spaces generates substantial stress, resulting in deformation of the substrate. The deformation measurement confirms that the deliquescence-crystallization pathway is very efficient in generating stress. The results of the present study indicate that the hydration of kieserite is always through solution, not a solid-state reaction, so the observed strain results from crystallization pressure in every case.

Steiger et al. (2008) report that hydration of hexahydrite may also be an important cause of damage: according to thermodynamic calculation, hydration of hexahydrite at $80 \% \mathrm{RH}$ and $25^{\circ} \mathrm{C}$ could cause a hydration pressure of $77 \mathrm{MPa}$, which greatly exceed the tensile strength of most building materials. Indeed, the pressure needed to suppress hydration corresponds to the upper bound of crystallization pressure (Flatt and Scherer 2002), and our results indicate that the latter is the cause of the observed strain.

\section{Materials and methods}

Magnesian Limestone is a Permian formation (250 millions years), composed of dolomitic rocks, that crops out in the North of England (counties of Yorkshire, Derbyshire and Nottinghamshire).

The Cadeby Stone is a light cream-colored stone classified as dolo-oomicrite with dolomite as major component and small amounts of other components, such as iron oxides, calcite and barium sulfates. The MIP data (Bourgès 2006) of this stone show a pore size distribution between 0.1 and $10 \mu \mathrm{m}$, and a total porosity measured by vacuum impregnation $\sim 21.5 \mathrm{vol} \%$. The amount of pores smaller than $0.1 \mu \mathrm{m}$ is negligible, while $89 \%$ of the porosity is formed by pores in the range from 0.1 to $5 \mu \mathrm{m}$. The sorptivity of this stone is $0.064 \pm 0.02 \mathrm{~cm} / \mathrm{min}^{1 / 2}$ and the capillary water uptake 15.7 vol\%.

The Highmoor stone is a dolo-microsparite white magnesian limestone consisting of fine dolomite crystals in micritic cements. Patches of dark iron oxide can be observed in thin sections. This stone has spherical pores and a homogeneous structure. The MIP data (Bourgès 2006) show a unimodal pore size distribution. The total porosity measured by vacuum impregnation is around $24.6 \pm 1.4 \%, 47 \%$ of the pores being larger than $5 \mu \mathrm{m}$. The amount of pores smaller than $0.1 \mu \mathrm{m}$ is negligible. The sorptivity of the stone is $0.055 \pm 0.02 \mathrm{~cm} / \mathrm{min}^{1 / 2}$ and the capillary water uptake 11.8 vol\%.

The measured hygric strain of both stones during water uptake is negligible. The static Young modulus and the tensile strength of Cadeby are $E=11.7 \pm 2.2 \mathrm{GPa}$ and $\sigma_{T}=5.5 \pm 0.5 \mathrm{MPa}$, respectively and those of Highmoor are $E=24.5 \pm 1.6 \mathrm{GPa}$ and $\sigma_{T}=9.7 \pm 0.9 \mathrm{MPa}$ (Bourgès 2006; Doehne 2010). Assuming that Poisson's ratio is $v=0.26$, the bulk modulus is $K \approx 8.14 \mathrm{GPa}$ for Cadeby and 17.0 GPa for Highmoor. Mavko et al. (1998) give values for the bulk modulus and shear modulus of dolomite $k_{s}=76.4 \mathrm{GPa}$ and $g_{s}=49.7 \mathrm{GPa}$. Thus, the Biot coefficient is $b=1-\mathrm{K} / k_{S} \approx 0.89$ for Cadeby and 0.78 for Highmoor.

According to Espinosa-Marzal et al. (2010), the macroscopic hydrostatic stress exerted by confined crystals in pores that leads to failure is $\sigma_{T} /(3(1-2 v))^{0.5}$, which is $5 \mathrm{MPa}$ for Cadeby and 8.1 MPa for Highmoor.

Magnesium sulfate solutions with concentrations $42 \%$ $\mathrm{w} / \mathrm{w}$, i.e. grams of salt per $100 \mathrm{~g}$ of water (abbreviated as MS42) and 18\% w/w (MS18) were prepared using DI water and anhydrous $\mathrm{MgSO}_{4}$ (Sigma-Aldrich).

Characterization of salt using thermogravimetric analysis and X-ray diffractometry

The goal of the TGA-XRD experiments was to determine the composition of the salt mixture that forms by drying a magnesium sulfate solution. Around $50 \mathrm{ml}$ of the MS42 solution was put in two different Petri dishes and placed in ovens at $40^{\circ} \mathrm{C}$, and $105^{\circ} \mathrm{C}$, respectively. A temperature of $105^{\circ} \mathrm{C}$ was selected, because it is commonly used as the drying temperature to impregnate stone with a determined amount of salt, since the fast drying rate reduces the formation of efflorescence. The drying temperature of $40^{\circ} \mathrm{C}$ was used, because it induces less severe drying, more similar to the drying conditions in the field. 
A qualitative estimation of the composition of the salt mixture during drying was performed by XRD. These analyses were carried out in a Siemens D5005 with a $\mathrm{CuK} \alpha$ radiation and patterns obtained by step scanning from $10^{\circ}$ to $45^{\circ} 2 \theta$ with a count of $0.1^{\circ}$ per step, $40 \mathrm{kV}$ and $30 \mathrm{~mA}$ in the X-ray tube.

TGA (TGA/SDTA 851e module, Mettler Toledo) was used to determine the amount of water in the salt mixture during drying. The temperature was raised from 30 to $400^{\circ} \mathrm{C}$ with heating rate of $10^{\circ} \mathrm{C} / \mathrm{min}$. In each measurement about $10 \mathrm{mg}$ of specimen were weighed in a $30 \mu \mathrm{l}$ alumina crucible. The salt, once placed in the crucible, was tamped with an aluminum pestle, and then covered with an aluminum lid with a hole. Our own results, as well as literature data, show that sample preparation and measurement conditions strongly affect the results and therefore our experiments were all performed under exactly the same conditions to allow comparison of our results.

Dilatation experiments with the thermomechanical analyzer

The expansion of Cadeby and Highmoor stones caused by the in-pore crystallization of $\mathrm{MgSO}_{4}$ salts during drying was measured on a TMA/SDTA841e (Mettler Toledo). Cylindrical samples were cut to a height of 6-8 $\mathrm{mm}$ and a diameter of $6 \mathrm{~mm}$. Each sample was initially impregnated with DI water for $10-12 \mathrm{~h}$ at $60^{\circ} \mathrm{C}$ and dried in the TMA to determine the coefficient of thermal expansion (CTE) of the stone. After that, the same sample was impregnated with magnesium sulfate solution (MS42 or MS18) at $60^{\circ} \mathrm{C}$ for the same period of time. Then, the surfaces of the sample were moistened with DI water at $60^{\circ} \mathrm{C}$ to remove salt from the surface and a drop of mineral oil was put on the top and bottom surfaces of the sample to avoid the occurrence of salt efflorescence during drying.

Prior to the drying, the furnace was equilibrated at $105^{\circ} \mathrm{C}$, the sample was placed in a glass sample holder, and the probe was lowered until it contacted the sample by applying a static force of $100 \mathrm{mN}$. The furnace was then lowered and the measurement started.

To generate a fast drying rate, the temperature was kept constant at $105^{\circ} \mathrm{C}$ for $120 \mathrm{~min}$. The goal of this drying method is to reduce salt mobilization and therefore to get a uniform salt distribution, since evaporation followed by crystallization takes place within the stone. After this isothermal hold, the temperature was lowered from 105 to $23^{\circ} \mathrm{C}$ at a cooling rate of $0.5^{\circ} \mathrm{C} / \mathrm{min}$ and finally maintained constant at $23^{\circ} \mathrm{C}$ for $90 \mathrm{~min}$. Length and temperature on the bottom surface were measured continuously. Similar experiments were performed by drying at $40^{\circ} \mathrm{C}$ for $5 \mathrm{~h}$.
Warping experiments

To investigate the deformation of the salt-bearing stone during re-wetting, a warping experiment was performed with Highmoor stone as described in (Espinosa-Marzal et al. 2010).

Stone plates $(10 \times 2.5 \times 1 \mathrm{~cm})$ were prepared with a known mass of kieserite by impregnating the plates with a magnesium sulfate solution (MS18) and then drying at $105^{\circ} \mathrm{C}$ for 8 weeks. The salt-bearing stone plates were glued to a piece of borosilicate glass (thickness $3.2 \mathrm{~mm}$ ) using epoxy (Epoxy 907 Adhesive System from MillerStephenson Chemical, thickness $\sim 0.5 \mathrm{~mm}$ ) to build a composite sample. The epoxy was tested by wetting a reference sample with water to see how long it would take to soften. The useful life of the set epoxy under the conditions of our experiments was found to be $15 \mathrm{~h}$.

The sample was mounted in a frame and held against a knife-edge and ball bearing support by two springs, so that the glass on top of the sample was in contact with an LVDT (see Fig. 1). The frame with the mounted stone-glass composite was placed in a vacuum desiccator. The purpose was to eliminate air from the pores of the stone prior to rewetting, to avoid trapping gas. After evacuating the chamber, $\mathrm{MgSO}_{4}$ solution $(18 \% \mathrm{w} / \mathrm{w})$ was pumped into the desiccator until the bottom surface of the sample was just touching the liquid. While the solution was being absorbed into the stone by capillary suction, the LVDT measured the deflection of the sample as it warped.

The overall mass of kieserite in the stone was measured gravimetrically and is expressed in the following in $\% \mathrm{w} / \mathrm{w}$, which means the grams of salt in $100 \mathrm{~g}$ dry and salt-free stone. All warping experiments were performed at $22 \pm 1.5^{\circ} \mathrm{C}$.

Environmental scanning electronic microscope in STEM mode

High magnification measurements to study the in situ kinetics of phase changes due to hydration and drying of $\mathrm{MgSO}_{4}$ were performed using an environmental scanning electron microscope (ESEM, FEI, Inc., Model XL30ESEM-FEG). The purpose of these experiments was to


Fig. 1 Warping setup (picture from Espinosa-Marzal et al. 2010) 
observe the hydration of single crystals of similar size as expected in the pores of the stone.

Salt particles that were synthesized by drying magnesium sulfate solutions at 105 and $40^{\circ} \mathrm{C}$ and characterized by TGA/XRD were placed on the copper grid and placed in the ESEM chamber at low vacuum (2 Torr). Condensationdrying cycles were performed by changing the chamber pressure from 5.5 to 2 Torr while maintaining the sample at constant temperature, $2^{\circ} \mathrm{C}$, using a cooling stage. Videos and images were recorded during the experiment.

\section{Experimental results}

Characterization of salt mixture

Figure 2 shows the evolution of the composition of the salt mixture that forms during drying of magnesium sulfate solution at 105 and $40^{\circ} \mathrm{C}$ and the average water content in moles per mole of anhydrous magnesium sulfate.

At $40^{\circ} \mathrm{C}$, only epsomite precipitates directly from the solution and is the only phase during the first 17 days of drying. Traces of hexahydrite, but mainly starkeyite, form from dehydration. Starkeyite is the only stable phase after 30 days of drying at $40^{\circ} \mathrm{C}$. No further dehydration takes place.

At $105^{\circ} \mathrm{C}$, epsomite first precipitates from the solution (30 $\mathrm{min})$ and, after $2 \mathrm{~h}$, hexahydrate also appears. Free water has completely evaporated after $4 \mathrm{~h}$. Then a mixture



Fig. 2 Evolution of the water content in moles per mole of anhydrous magnesium sulfate in the salt mixture during drying at $105^{\circ} \mathrm{C}$ (circles) and $40^{\circ} \mathrm{C}$ (triangles) determined by TGA. The composition of the salt mixtures determined by XRD is also shown in this diagram of lower hydrates that result from the dehydration of epsomite and hexahydrite is identified by XRD. By progressive drying (and dehydration) the crystalline salt mixture consists only of kieserite and $\mathrm{MgSO}_{4} \cdot 1.25 \mathrm{H}_{2} \mathrm{O}$.

The average water content after 43 days of drying at $105^{\circ} \mathrm{C}$ is $1.07 \mathrm{~mol}$ per mole of $\mathrm{MgSO}_{4}$. The TGA curve measured after 43 days of drying reveals two dehydration steps, consisting of the dehydration of $\mathrm{MgSO}_{4} \cdot 1.25 \mathrm{H}_{2} \mathrm{O}$ $(15 \%)$ and kieserite $(85 \%)$. We expect that prolonged drying of this salt mixture might lead to pure kieserite.

Dilatation experiments with the TMA

Figure 3 shows the deformation of a Cadeby stone sample impregnated with water and with salt solution (MS42) during drying at $105^{\circ} \mathrm{C}$ and following cooling to room temperature. The deformation is caused by the change of temperature and by the pressure exerted by the confined magnesium sulfate salts. The weight loss of the sample was determined in an accompanying experiment under the same drying conditions, showing that after $2 \mathrm{~h}$ at $105^{\circ} \mathrm{C}$ the stone is only partially dried: the samples contain an average of $\sim 3$ mol water per mole of $\mathrm{MgSO}_{4}$. During the following cooling to $23^{\circ} \mathrm{C}$, the weight remains constant.

The CTE of the salt-free stone is $12.0 \pm 0.4 \mu \mathrm{m} / \mathrm{m}^{\circ} \mathrm{C}$. The CTE of the salt-bearing stone is expected to be larger, since salt crystals generally have a larger CTE than carbonate stones (e.g., CTE of kieserite is $22 \mu \mathrm{m} / \mathrm{m}^{\circ} \mathrm{C}$ according to Haynes (2005)). The composite model according to Hashin (1983) predicts the CTE of the saltbearing stone as a function of the volume fraction of stone



Fig. 3 Measured deformation of Cadeby stone impregnated with water and with magnesium sulfate solution MS42\% during drying at $105^{\circ} \mathrm{C}$ and following cooling down 
and salt. Given the small amount of salt in the stone $(<3 \%$ w/w), the CTE can be considered to remain unchanged.

Taking into account the initial thermal deformation, an additional expansion (up to $\sim 360 \pm 40 \mu \mathrm{m} / \mathrm{m}$ ) is measured, owing to the growing crystals (mainly epsomite and hexahydrite according to the previous discussion) exerting a pressure on the pore wall (Espinosa-Marzal and Scherer 2009; Espinosa-Marzal et al. 2010). Subsequently, a fast relaxation, followed by a much slower relaxation, is observed. According to the TGA/XRD results at $105^{\circ} \mathrm{C}$, a gradual and slow dehydration takes place, which has to be related to the observed relaxation and is confirmed by the weight loss in the accompanying experiment. The cooling down from 105 to $20^{\circ} \mathrm{C}$ is responsible for the negative thermal strain at the end of the experiment in both samples. At the end of the experiment the strain difference between the salt-free and salt-bearing stone is $\sim 230 \mu \mathrm{m} / \mathrm{m}$, which is caused by the precipitated salt.

Similar TMA experiments were performed with stone impregnated with MS18. The measured expansion of the salt-impregnated sample is much smaller than in the previous example, almost negligible when compared to the expansion of the water-saturated sample. This is attributed to the smaller salt content in the sample, since the thermal expansion coefficient of the salt-free sample is the same.

In the following set of TMA experiments (Fig. 4), drying of stone impregnated with MS18 was performed at $40^{\circ} \mathrm{C}$ for $6 \mathrm{~h}$, followed by a cooling to $18^{\circ} \mathrm{C}$ (see Fig. 4). The initial contraction of the water-saturated sample is caused by the cooling, since impregnation took place at $60^{\circ} \mathrm{C}$. The final negative strain is also caused by the thermal contraction during cooling.

The accompanying drying experiment indicates that $\sim 6-8 \mathrm{~mol}$ of water per mol of $\mathrm{MgSO}_{4}$ are still present in the salt-bearing sample at the end of the experiment. According to the TGA/XRD experiments, epsomite is the main salt phase as long as solution is present. In the pores where water has completely evaporated, starkeyite is expected to form from dehydration.

During drying at $40^{\circ} \mathrm{C}$, the expansion induced by the crystallization of epsomite increases remarkably after $140 \mathrm{~min}$ at constant temperature in all samples. A plateau is reached by $\sim 300 \mathrm{~min}$, which indicates the end of the crystallization; following this, the sample contracts during cooling. The strain difference between the salt-free and salt-bearing stone is $\sim 600 \mu \mathrm{m} / \mathrm{m}$ which implies substantial damage; however, we could not identify damage after the experiment. The bare Cadeby stone already has a lot of cracks and imperfections, so this significant deformation and residual strain might be caused by the propagation of the pre-existing cracks. No plateau is reached at $18^{\circ} \mathrm{C}$, which indicates that dehydration is not completed yet. The results obtained with the Highmoor stone were similar.

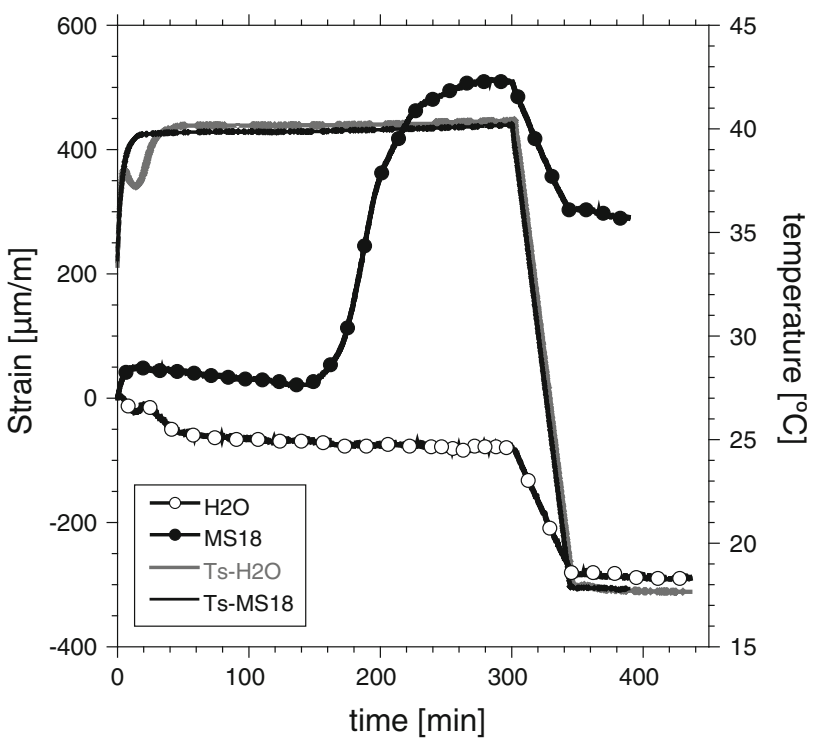

Fig. 4 Measured deformation of Cadeby stone impregnated with magnesium sulfate solution MS18\% and with water during drying at the given temperature

Rewetting experiments with the warping set-up

The stone plates contain $0.61 \pm 0.02 \% \mathrm{w} / \mathrm{w}$ salt after 8 weeks of drying. According to our previous results, we expect that mainly kieserite, but also other lower hydrates, fill the pores of the stone. Figure 5 shows the deflection of the stone-glass composite during the uptake of magnesium sulfate solution at $23^{\circ} \mathrm{C}$. The measured deflection is the result of the hindered deformation of the stone during the rewetting of salt. A negative (downward) deflection $\left(\Delta_{\exp }<0\right)$ indicates that the warping sample becomes concave up, due to the expansion of the stone partially hindered by the glass, and a positive (upward) deflection $\left(\Delta_{\exp }>0\right)$ means that the sample becomes convex up, due to the contraction of the stone (see Espinosa-Marzal et al. 2010).

In Espinosa-Marzal et al. (2010), where similar stone/ glass composites were impregnated with sodium sulfate, it was explained that the stone plate is initially under stress and deformed by the crystallization pressure from thenardite in the pores of the stone. As water enters the stone, this salt is dissolved, which accounts for the initial upward warping of those samples. In contrast during the rewetting of magnesium sulfate salts, there is no initial upward deflection, but only a significant downward deflection and, finally, a progressive decrease of the deflection (see Fig. 5).

Indeed, the TMA experiments show that although drying-induced crystallization of epsomite and hexahydrite at $105^{\circ} \mathrm{C}$ leads initially to an expansion and so to stress, the progressive (and slow) dehydration to lower hydrates leads to a relaxation of the stress. Hence, this explains that the residual stress after the prolonged drying of the stone plates 


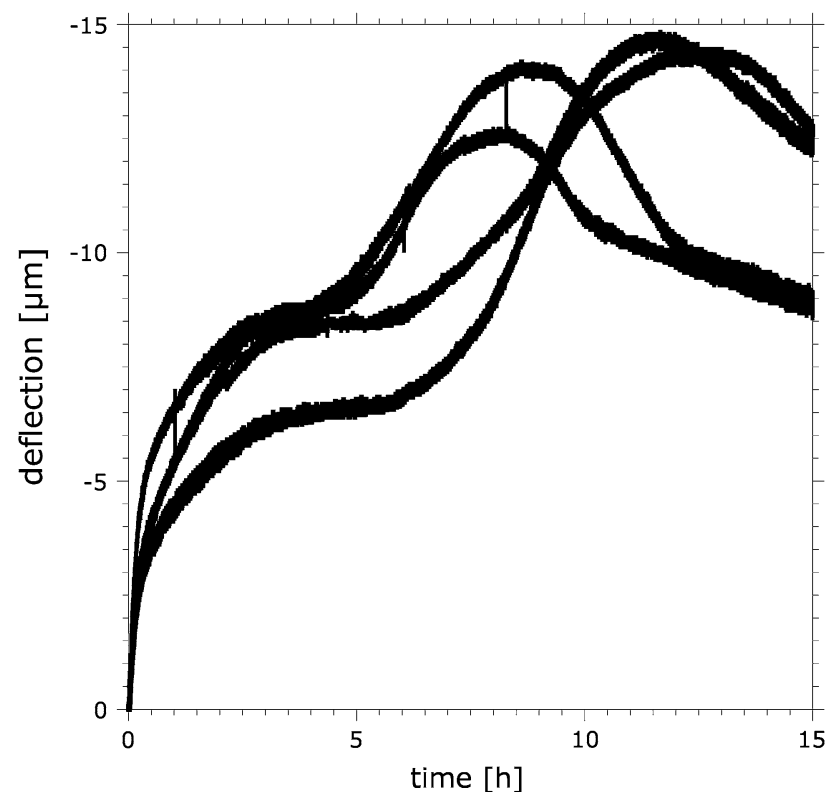

Fig. 5 Measured deflection of four different stone plates containing $0.6 \% \mathrm{w} / \mathrm{w}$ of lower hydrates of $\mathrm{Mg}$ sulfate during re-wetting with MS18

becomes gradually smaller, eventually vanishes and no upward deflection is measured during the re-wetting.

Figure 5 shows the negative deflection during the uptake of solution in four experiments, where all four stone plates contain a similar amount of salt. Thus, confined crystals exert a pressure on the pore walls, producing an expansion in the stone plate that is hindered by the glass and results in a downward (negative) deflection, reaching a maximum at $-15 \mu \mathrm{m}$ within $8-11 \mathrm{~h}$. The thermodynamically stable salt at the temperature of the experiment $\left(22^{\circ} \mathrm{C}\right)$ is epsomite. However, the solution is also supersaturated with respect to the metastable hexahydrite, and therefore we cannot exclude that in-pore crystallization of hexahydrite, or of a mixture, is responsible for the observed deflection. Indeed, re-wetting of kieserite was investigated with an optical microscope, which revealed the precipitation of a metastable phase (most likely hexahydrite) that transformed to epsomite when touched with an epsomite crystal. Thus, it is not known which phase (epsomite or hexahydrite) forms within the pores and leads to the deformation. It is possible that hexahydrite crystallizes first, and its hydration leads to the precipitation of epsomite; this re-crystallization in two steps could account for the plateau observed after around $5 \mathrm{~h}$ and the following deflection.

It takes $8-11 \mathrm{~h}$ for the deflection to reach its maximal value. In contrast, the measured deflection during the rewetting of limestone impregnated with thenardite reaches the maximum after $1-2 \mathrm{~h}$, both re-wetting processes leading to similar magnitudes of the deflection $(\approx-15 \mu \mathrm{m})$. It is shown by Espinosa-Marzal et al. (2010) that the solution transport significantly affects the time dependence of the re-crystallization process and the consequent deflection rate. Thus, the high viscosity of the magnesium sulfate solution (Ruiz-Agudo et al. 2007a), in addition to the significant pore-clogging (Espinosa-Marzal and Scherer 2008b) induced by $\mathrm{MgSO}_{4}$ salts, explains the retardation of the re-crystallization process in these experiments which leads to the observed slow deformation.

Wetting and drying of magnesium sulfate salts in SEM/STEM mode

Single crystals of a salt mixture $(72 \%$ kieserite and $28 \%$ $\mathrm{MgSO}_{4} \cdot 1.25 \mathrm{H}_{2} \mathrm{O}$ ) were analyzed in the ESEM in STEM mode. The chamber was held at $2^{\circ} \mathrm{C}$ for the whole experiment with an initial pressure of 2 Torr. At this temperature, the hydration humidity threshold from kieserite to hexahydrite and epsomite is $\sim 29 \%$ (Steiger and Linnow 2008). Literature data indicate that kieserite transforms first into hexahydrate and not directly into epsomite (Chipera and Vaniman 2007).

Initially, the sample was kept at around $40 \% \mathrm{RH}$ for $5 \mathrm{~h}$. After this time an image was taken that showed the presence of solution in which crystal faces were visible (Fig. 6a). The phase formed at $40 \% \mathrm{RH}$ results from the hydration of (most probably) kieserite into hexahydrite, which takes place above 29\% RH according to Wang et al. (2009).

By increasing the vapor pressure step-by-step, a recrystallization of the hexahydrite crystals through the condensed film was observed when reaching 95\% RH. The humidity was kept at $95 \%$ for $7 \mathrm{~min}$. In the first $3.5 \mathrm{~min}$ the crystals absorbed all the liquid film surrounding them (Fig. 6c, d), leading to two new well-developed crystals (Fig. 6e). As soon as the water film was completely absorbed, the two crystals started to expand (Fig. 6f). The resolution does not permit us to say whether a new phase formed on the original, or whether microcracking of the product occurred. The hydration process lasted for $3 \mathrm{~min}$, after which the two crystals went through deliquescence. Indeed, 94\% RH corresponds to the deliquescence humidity of epsomite at $2^{\circ} \mathrm{C}$ (Steiger and Linnow 2008).

Deliquescence of epsomite was reached in less than a minute (Fig. 6g). The pressure was then increased to above $100 \%$ to ensure complete deliquescence. Once the RH was brought below $100 \%$, the drop of solution immediately shrank, but no crystals were visible, contrary to expectations.

Similar experiments were performed with grains of agglomerated salt crystals (size $\sim 100 \mu \mathrm{m}$ ) in the ESEM. Here, a very slow expansion (over hours) took place as the humidity was increased step-by-step up to $100 \%$. The deliquescence was extremely slow and was not completed after $4 \mathrm{~h}$. It was observed that smaller clusters of salts went into deliquescence much faster; that is, the deliquescence 

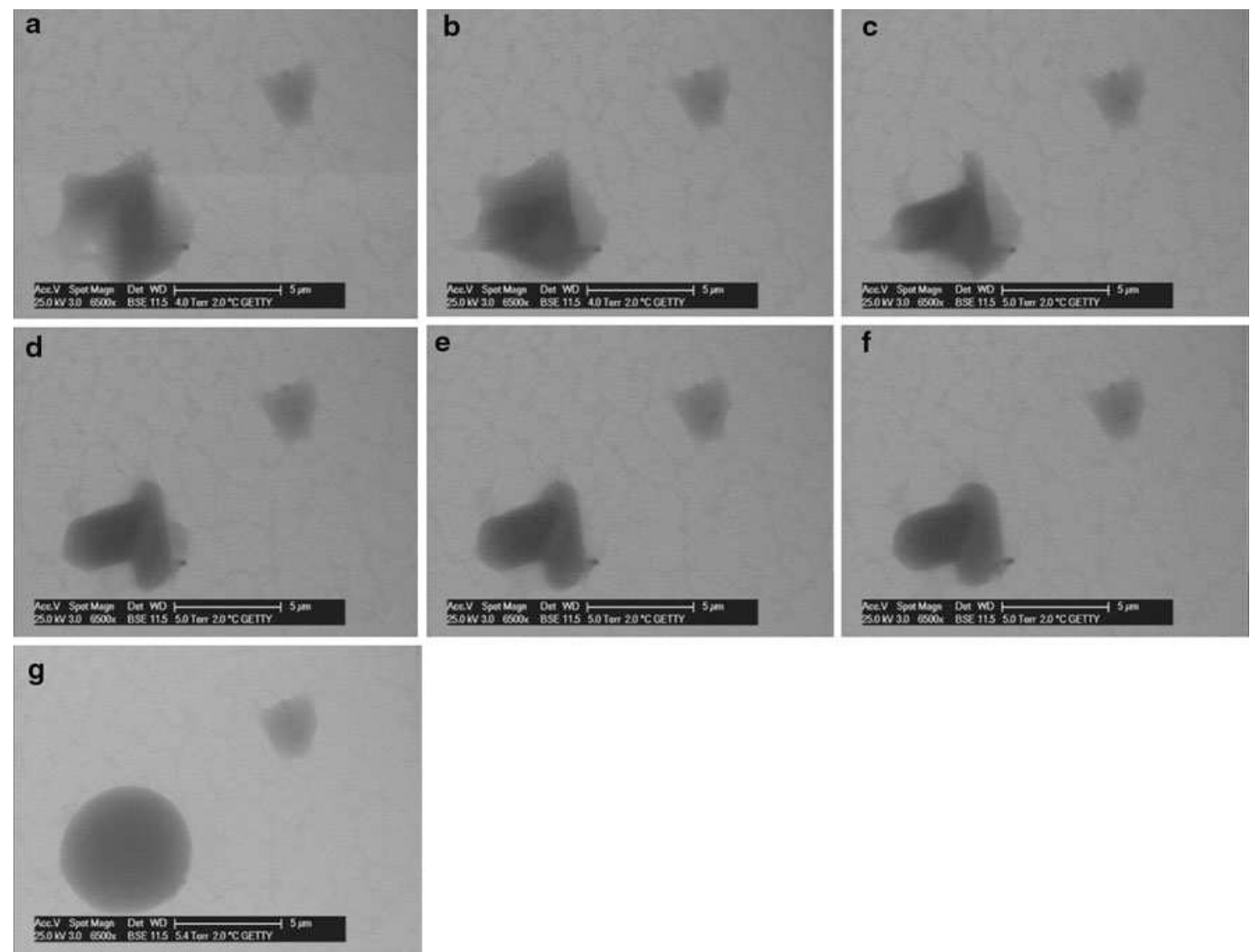

Fig. 6 STEM-images obtained during the wetting from 40 to $95 \% \mathrm{RH}$ of a sample formed by $78 \%$ kieserite and $22 \% \mathrm{MgSO}_{4} \cdot 1.25 \mathrm{H}_{2} \mathrm{O}$

kinetics of the grains is size-dependent. This retardation of the transformation is related to the hindered transport of water and vapor through the agglomerated crystals. This does not occur in the smaller single crystals (used in the STEM experiments) for which the transformation is faster.

\section{Discussion}

Significant deformations of two dolomitic limestones have been measured during drying and re-wetting experiments of $\mathrm{MgSO}_{4}$-bearing stone, which indicates that magnesium sulfate salts are capable of exerting stress in the stone during crystallization and hydration.

To elucidate the mechanism through which stress is induced, we first determined the composition of the salt mixture formed by drying magnesium sulfate solutions at different temperatures. Our results show that only epsomite and hexahydrite precipitate directly from solution when drying at temperatures between 40 and $105^{\circ} \mathrm{C}$ and low $\mathrm{RH}$. The thermodynamically stable salt, kieserite, forms only during dehydration of more highly hydrated phases by prolonged drying at $105^{\circ} \mathrm{C}$ (see Fig. 1). Experiments at $60^{\circ} \mathrm{C}$, not shown here, are in agreement with this.
In contrast to sodium sulfate, drying-induced crystallization does not lead to confined lower hydrates (thenardite, in case of sodium sulfate), but only to crystallization of hexahydrite and epsomite, which lead to remarkable stresses, as measured in the TMA experiments. These phases dehydrate by continuous drying and therefore a relaxation of the stress is observed, which has also to be expected in the field during drying. This gives a different crystallization and damage pattern for magnesium sulfate salts compared to that of the sodium sulfate salts.

The measured expansion during the crystallization of epsomite at $40^{\circ} \mathrm{C}$ is huge. There is no appreciable relaxation, which indicates that dehydration to starkeyite, as expected from Fig. 1, is not significant yet. This is confirmed by the high water content of the TMA samples, even after $6 \mathrm{~h}$ of drying ( $\sim 6.5-8 \mathrm{~mol}$ of water per mol of $\mathrm{MgSO}_{4}$ ).

According to all these results, it is reasonable to expect that kieserite will not form in the field and therefore kieserite cannot cause damage to stone in the field. Hexahydrite will form from dehydration of epsomite by gentle drying. If severe and prolonged drying occurs, starkeyite will form in the pores of the stones from dehydration of epsomite and hexahydrite. Dehydration will reduce the 
volume of salt and contribute to relaxation of any existing crystallization pressure.

One question that arises from our results is the duration of hydration and dehydration. STEM and ESEM experiments clearly show the size-dependent kinetics of hydration: re-crystallization of single crystals and deliquescence takes place rapidly, within seconds, while hydration and deliquescence of agglomerated crystals seems to be hindered kinetically by liquid transport though the clusters. This also explains why the dehydration of the salt in the bulk experiments (in Petri dishes) takes months. In porous materials, we can expect single crystals whose sizes are limited by the pore diameter, and therefore faster transformation, comparable to that observed for small single crystals, but limited by the rate of transport through the pore network.

The XRD measurements by Steiger and Linnow (2008) show that at high RH kieserite hydrates to hexahydrite and finally hexahydrite into epsomite. We have seen by ESEM/ STEM that even at low RH (40\%) there is an adsorbed liquid film on the crystal surface, meaning that the hydration of kieserite takes place through the solution. Consequently, it is reasonable to assume that the re-wetting of kieserite (with water or solution) follows the same recrystallization path during the warping experiment. Thus, we assume that first hexahydrite precipitates from the solution causing a deflection of $\sim 8 \mu \mathrm{m}$, while the hydration from hexahydrite to epsomite is responsible for the second increase of the deflection after the first plateau which is of similar magnitude. This indicates that the rewetting of hexahydrite in the field can lead to large stresses.

Mechanical analysis of the deflection of the composite formed by the glass plate and the stone (Espinosa-Marzal et al. 2010) relates the deflection to the strain in the stone, $\Delta e$, induced by the salt crystals. Applying the theory of poroelasticity, the stress in the stone, $s$, is related to the crystallization-induced deformation by $s \approx 3 \mathrm{~K} \Delta e$. The minimal deformation of the stone that would produce the total deflection $(\approx 14 \mu \mathrm{m})$ is obtained by assuming a uniform distribution of magnesium sulfate salts (hexahydrite and epsomite) in the stone. However, the invading solution is too dilute to permit uniform precipitation of salt throughout the volume and a non-uniform salt distribution is expected.

Figure 7 shows the estimated stress as a function of the depth of the crystallization region in Highmoor stone. The stress becomes larger than the tensile strength $(8.1 \mathrm{MPa})$ if salt precipitates in a narrower region $(<4 \mathrm{~mm})$. In our experiment, there is no damage, since the deformation that would result from crystallization within the stone is hindered by the glass plate. If the deformation is not hindered, damage can be expected at low salt content $(0.6 \% \mathrm{w} / \mathrm{w}$ of

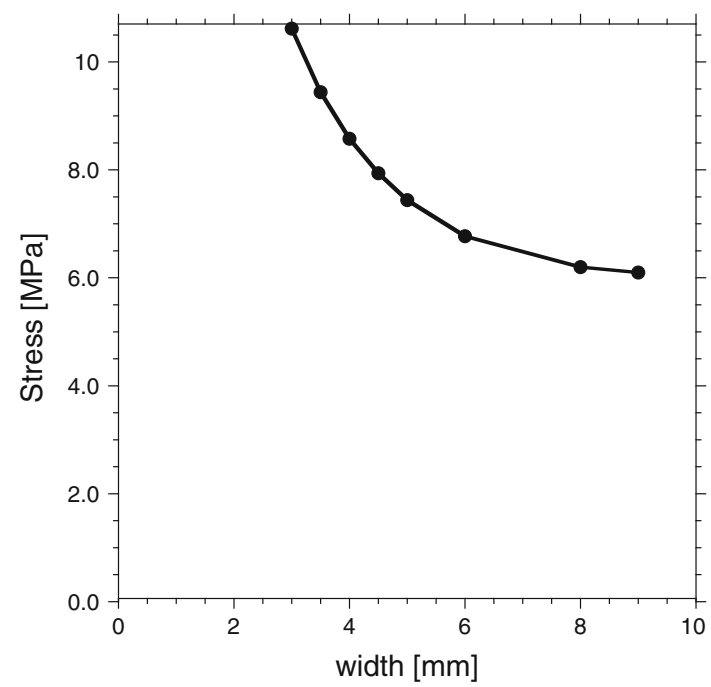

Fig. 7 Estimated crystallization pressure exerted by hexahydrite and resulting stress during the warping experiment. The horizontal axis is the width of the region over which salt precipitates in the $10 \mathrm{~mm}$ plate of stone. Thus, if width $=4$, the salt grows in a region $4 \mathrm{~mm}$ wide, lying between 6 and $10 \mathrm{~mm}$ below the exposed surface

kieserite in our experiment) depending on the salt distribution which will be affected by the permeability of the stone and the viscosity of the solution. In the field, it is also possible that salt concentrates close to the stone surface, while the salt-free substrate partially hinder the deformation. That means that a larger salt content would be necessary to cause damage.

Unfortunately, it has not been possible to investigate the deformation caused by the re-crystallization of starkeyite into hexahydrite/epsomite. The solubility of starkeyite at $20^{\circ} \mathrm{C}$ is slightly smaller than that of kieserite $(5.0$ vs. $5.6 \mathrm{~mol} / \mathrm{kg}$, according to Spencer 2000) and therefore very similar stresses should be expected during re-wetting of starkeyite, if confined epsomite or hexahydrite precipitates from a solution saturated with respect to starkeyite, as compared to kieserite.

As reported for thenardite by Espinosa-Marzal et al. (2010), the re-crystallization process is strongly related to the solution transport. The permeability of the stone does clearly affect the deformation rate, as was shown when comparing the rewetting of two limestones with different permeabilities. The permeability of the dolomitic limestones is comparable with those limestones, but the process is much slower. On the other hand, the STEM experiments show that the re-crystallization of small crystals is very rapid. Therefore, we conclude that the high viscosity of the solution, together with pore-clogging, are the main factors retarding the re-crystallization of kieserite into hexahydrite/epsomite.

The slow transport of magnesium sulfate solution during rewetting will lead to a particular crystallization and 
damage pattern compared to other salts. For example, if water is provided from rain, a crystallization front close to the surface will be expected, even if the permeability of the stone is high. On the other hand, if the water proceeds from ground water, crystallization will not be expected to occur close to the surface, but within the stone, which will be more damaging, as observed in the capillary rise experiment reported by Ruiz-Agudo et al. (2007a).

When re-wetting of lower hydrates occurs in the field, where environmental conditions are continuously changing, the re-crystallization process could be interrupted (e.g., by drying) and therefore not be completed. This could significantly retard the damage evolution. The expansion would be smaller, and damage could be caused by fatigue after repeated re-wetting/drying periods.

The movies recorded in STEM mode show that the recrystallization proceeds clearly through the water film surrounding the crystal $(\sim 5 \mu \mathrm{m})$. The presence of the water film and the re-crystallization by adsorption of liquid water indicate that hydration is a through-solution process, even at $40 \% \mathrm{RH}$. This also demonstrates that if salt hydration takes place in the pores of stone, the crystals can exert crystallization pressure, stress, and eventually damage.

By decreasing the relative humidity in the ESEM chamber, we observed shrinkage of the droplet of solution that had formed by deliquescence of epsomite, but no crystals were visible. It is possible that, at high drying rates, the rapid increase in viscosity hinders the nucleation of epsomite (Espinosa-Marzal and Scherer 2010). The cause of the observed shrinkage of the solution during drying is currently under investigation.

\section{Conclusions}

The drying and re-wetting experiments performed show that stress can be generated by crystallization and hydration of magnesium sulfate salts, the crystallization pressure being responsible for the stress. Since only epsomite and hexahydrite precipitate from solution, only these salts can be expected to cause damage, while lower hydrates form during dehydration and therefore cause stress relaxation. The measured deformations are significant, although the salt content is small, indicating that larger amounts of salt could lead to immediate damage, while lower amounts of salt might cause damage by fatigue after more dryingrewetting cycles. These results indicate that magnesium sulfate salts are prone to cause damage in the field upon drying and during condensation or uptake of rain and ground water. In comparison to other salts, such as sodium sulfate, a slower damage evolution can be expected during re-wetting. This is owing to the high viscosity of the solution, which retards solution transport and crystal nucleation, and to pore-clogging, which retards hydration and deliquescence.

Prediction of salt weathering in the field is only possible if the interaction between stone properties, environmental conditions and composition of the salt mixtures and fluid phases are considered. Even in such a simple experiment as the re-wetting of $\mathrm{MgSO}_{4}$ salts, the interacting phenomena (transport, dissolution, crystallization, deliquescence) can only be considered by numerical modeling. This makes it difficult to characterize materials as not susceptible to salt damage according to a laboratory experiment, since under particular conditions (and history) they might become susceptible. The factors for the numerical modeling are available (e.g. Sghaier and Prat 2010; Espinosa-Marzal and Scherer 2009, 2010), but the model parameters are only known for specific scenarios. Indeed, more knowledge of the kinetics of crystallization and dissolution of crystals within the pore network, the influence of pore-clogging on the transport of the solution, and of the properties of the confined solution between the minerals exerting pressure is still necessary to generalize these models for predictions in the field.

Acknowledgments The authors wish to acknowledge the financial support of this research provided by the Getty Conservation Institute and by the Deutsche Forschungsgemeinschaft.

\section{References}

Bourgès A (2006) Holistic correlation of physical and mechanical properties of selected natural stones for assessing durability and weathering in the natural environment. Dissertation, LudwigsMaximilians-Universität München

Chatterji S, Jensen AD (1989) Efflorescence and breakdown of building materials. Nordic Concr Res 8:56-61

Chipera SJ, Vaniman DT (2007) Experimental stability of magnesium sulfate hydrates that may be present on Mars. Geochim Cosmochim Acta 71:241-250

Clark BC, Van Hart DC (1981) The salts of Mars. Icarus 45:370-378

Cooke R, Warren A, Goudie A (1993) Desert geomorphology. UCL Press, London

Correns CW, Steinborn W (1939) Experimente zur Messung und Erklärung der sogenannten Kristallisationskraft. Z Krist (A) 101:117-133

Coussy O (2006) Deformation and stress from in-pore drying-induced crystallization of salt. J Mech Phys Solids 54:1517-1547

CRC-Handbook of Handbook of Chemistry and Physics (2008) 88th edn. http://www.hbcpnetbase.com

Doehne E (2010) Private communication

Doehne E, Pinchin S (2008) Time-lapse macro-imaging in the field: monitoring rapid flaking of magnesian limestone. In: Lukaszewicz J, Niemcewicz P (eds) Proceedings of the 11th international congress on deterioration and conservation of stone. Torun Nicolaus Copernicus University Press, vol 1, pp 365-372

Espinosa-Marzal RM, Scherer GW (2008a) Study of sodium sulfate salts crystallization in limestone. Env Geol 56:605-621. doi:10.1007/s00254-008-1441-7 
Espinosa-Marzal RM, Scherer GW (2008b) Study of the pore clogging induced by salt crystallization in Indiana limestone. In: Proceedings of 11 th international congress deterioration and conservation of stone, Nicolaus Copernicus University Press, Torun, Poland, vol I, pp 81-88

Espinosa-Marzal RM, Scherer GW (2009) Crystallization pressure exerted by in-pore confined crystals, poromechanics IV. In: Ling HI, Smyth A, Betti R (eds) Proceedings of fourth biot conference on poromechanics, New York, 2009. DEStech Publications, Lancaster, PA, pp 1013-1018

Espinosa-Marzal RM, Scherer GW (2010) Advances in understanding damage by crystallization. Acc Chem Res 43(6):897-905. doi: 10.1021/ar9002224

Espinosa-Marzal RM, Hamilton A, McNall MR, Whitaker K, Scherer GW (2010) The chemomechanics of sodium sulfate crystallization in thenardite impregnated limestones during re-wetting (in preparation)

Evans IS (1969) Salt crystallization and rock weathering. Rev Géomorphologie dynamique XIX 4:153-177

Feldman WC, Mellon MT, Maurice S, Prettyman TH, Carey JW, Vaniman DT, Bish DL, Fialips CI, Chipera SJ, Kargel JS, Elphic RC, Funsten HO, Lawrence DJ, Tokar RL (2004) Hydrated states of $\mathrm{MgSO}_{4}$ at equatorial latitudes on Mars. Geophys Res Lett 31:L16702. doi:10.1029/2004GL020181

Flatt RJ (2002) Salt damage in porous materials: how high supersaturations are generated. J Cryst Growth 242:435-454

Flatt RJ, Scherer GW (2002) Hydration and crystallization pressure of sodium sulfate: a critical review. In: Vandiver PB, Goodway M, Mass JL (eds) Materials issues in art and archaeology VI, MRS symposium proceedings, vol 712. Materials Research Society, Warrendale, PA, pp 29-34

Foster W, Hoover KW (1963) Hexahydrite $\left(\mathrm{MgSO}_{4} \cdot 6 \mathrm{H}_{2} \mathrm{O}\right)$ as an efflorescence of some Ohio dolomites. Ohio J Sci 63:152-158

Gooding JL (1992) Soil mineralogy and chemistry on mars" possible clues from salts and clays in SNC meteorites. Icarus 99:28-41

Goudie AS (1985) Salt weathering, Research Paper, School of Geography, University of Oxford, 31-33

Goudie A, Viles H (1997) Salt weathering hazards. Wiley, Chichester, p 241

Goudie A, Cooke R, Evans I (1970) Experimental investigation of rock weathering by salts. Area 2:42-48

Hashin Z (1983) Analysis of composite materials-a survey. J App Mech 50:481-505

Haynes H (2005) ASTM C 88 Test on soundness of aggregate using sodium sulfate or magnesium sulfate: a study of the mechanisms of Damage. JAI 2(1):1-17

Heide K (1969) Thermochemische und kinetisce Untersuchungen der endothermlen Umbildungsreaktionen des Epsomits $\left(\mathrm{MgSO}_{4}\right.$. $\left.7 \mathrm{H}_{2} \mathrm{O}\right)$. J Therm Anal 1:183-194
Lopez-Arce P, Garcia-Guinea J, Benavente D, Tormo L, Doehne E (2008) Deterioration of dolostone by magnesium sulfate salt: an example of incompatible building materials at Bonaval Monastery, Spain. Constr Build Mater 23:846-855

Mavko G, Mukerji T, Dvorkin J (1998) The Rock physics handbook. Cambridge University Press

Paulik J, Paulik F, Arnold M (1981) Dehydration of magnesium sulfate heptahydrate investigated by quasi isothermal-quasi isobaric TG. Thermochim Acta 50:105-110

Rodriguez-Navarro C, Doehne E (1999) Salt weathering: influence of evaporation rate, supersaturation and crystallization pattern. Earth Surf Process Landforms 24:191-209

Ruiz-Agudo E, Mees F, Jacobs P, Rodriguez-Navarro C (2007a) The role of saline solution properties on porous limestone salt weathering by magnesium and sodium sulfates. Environ Geol 52:269-281

Ruiz-Agudo E, Martin-Ramos D, Rodriguez-Navarro C (2007b) Mechanism and kinetics of dehydration of epsomite crystals formed in the presence of organic additives. J Phys Chem B 111:41-52. doi:10.1021/jp064460b

Scherer GW (2004) Stress from crystallization of salt. Cement Concr Res 34:1613-1624

Sghaier N, Prat M (2010) Effect of efflorescence formation on drying kinetics of porous media. Transp Porous Med 80:441-454

Spencer RJ (2000) Sulfate minerals in evaporite deposits. In: Alpers CN, Jambor JL, Nordstrom DK (eds) Sulfate minerals: crystallography, geochemistry, and environmental significance, reviews in mineralogy and geochemistry, vol 40. Mineralogical Society of America, Washington DC, pp 173-192

Steiger M (2005a) Crystal growth in porous materials-I: the crystallization pressure of large crystals. J Cryst Growth 282:455-469

Steiger M (2005b) Crystal growth in porous materials-II: influence of crystal size on the crystallization pressure. J Cryst Growth 282:470-481

Steiger M, Linnow $\mathrm{K}$ (2008) Hydration of $\mathrm{MgSO}_{4} \cdot \mathrm{H}_{2} \mathrm{O}$ and generation of stress in porous materials. Cryst Growth Des $8: 336-343$

Steiger M, Linnow K, Juling H, Gülker G, El Jarad A, Brüggerhoff S, Kirchner D (2008) Hydration of $\mathrm{MgSO}_{4} \cdot \mathrm{H}_{2} \mathrm{O}$ and generation of stress in porous materials. Growth Des 8:336-343

Vaniman DT, Bish DL, Chipera SJ, Fialips CI, Carey JW, Feldman WC (2004) Magnesium sulfate salts and the history of water on Mars. Nature 431:663-665

Wang A, Freeman JJ, Jolliff BL (2009) Phase transition pathways of the hydrates of magnesium sulfate in the temperature range $50^{\circ} \mathrm{C}$ to $5^{\circ} \mathrm{C}$ : implication for sulfates on mars. J Geophys Res $114: 1-28$ 